\title{
Note on Sustainability Prices When Sectoral Growth Rates Differ
}

\author{
Carlo D'Adda ${ }^{1}$
}

Received: 15 April 2015 / Accepted: 28 September 2015 / Published online: 10 November 2015 (C) Società Italiana degli Economisti (Italian Economic Association) 2015

\begin{abstract}
A dynamic Leontief-type model is considered. The sectoral growth rates differ. This note shows that the dual of the (vector) equation connecting sectoral products and sectoral consumptions is a (vector) price equation representing sustainability prices, i.e. prices assuring profits that are consistent with the cost of sectoral capital adjustments. In this economy the sectoral price levels depend on the sectoral growth rates and the sectoral profit-capital rates differ.
\end{abstract}

Keywords Dynamic Leontief model - Sustainability prices versus Natural prices · Vertically integrated sectors

\section{JEL Classification D46 D D57}

What explains the different growth rates of a multisectoral economy over the time is obviously not nature, but human behaviour. An inspiring intuition may be offered by the robust empirical finding according to which different consumption categories grow with different income elasticities over time. For our purpose, that is understanding

\footnotetext{
Even if self-contained the present note originates from further reflection after a recent essay of mine (D'Adda 2015). I wish to thank Salvatore Baldone and Roberto Scazzieri for reading and discussing the note with me and most of all Luigi Pasinetti who drew my attention to Pasinetti (1988) whose relevance at the time of writing had escaped to me. My thanks also to the anonymous referee.

$凶$ Carlo D’Adda

carlo.dadda@unibo.it

1 Department of Economic Sciences, University of Bologna, Strada Maggiore 45, 40125 Bologna, Italy
} 
sectoral long run prices, we consider a set (vector) of different sectoral real growth rates that we take as known over a given time horizon. ${ }^{1}$

In order to describe the working of the economy a dynamic Leontief-type model may be taken as a departure point. The first equation below shows the connection between the production vector and the consumption vector

$$
\mathbf{q}=\mathbf{A q}+\mathbf{K G q}+\mathbf{c}=(\mathbf{I}-\mathbf{A}-\mathbf{K G})^{-1} \mathbf{c}
$$

The second equation (so called dual of the first one) shows how the price vector depends upon labour requirements and the unit wage

$$
\mathbf{p}=\mathbf{A}^{\prime} \mathbf{p}+\mathbf{G} \mathbf{K}^{\prime} \mathbf{p}+w \mathbf{l}=\left(\mathbf{I}-\mathbf{A}^{\prime}-\mathbf{G} \mathbf{K}^{\prime}\right)^{-1} w \mathbf{l}
$$

The meaning of the symbols is as follows:

A matrix of current inputs in sectoral production processes,

c column vector of final consumptions of the sectoral products,

K matrix of capital stocks per unit of sectoral product,

l column vector of the labour coefficients (for ex. labour hours) for sectoral product unit,

p column vector of sectoral prices,

q column vector of sectoral products,

g column vector of the sectoral product growth rates,

G diagonal matrix of the sectoral product growth rates,

w scalar representing the contractual wage per labour unit (assumed given and uniform), transposition symbol.

For the sake of simplicity we think of a closed economy, the public sector is not explicitly taken into account and capital is not subject to physical decay.

Some concise notations are in order:

1. The assumption of given sectoral growth rates represents a convenient stylization (for a non-infinite time span) of a world where sectoral consumptions show different income elasticities (as in Pasinetti 1973). For example in order to explore the future evolution of the economic system over the next decade, the vector of sectoral growth rates might be chosen equal (or similar) to the one of the previous decade.

2. In order for the previous assumption (point 1) to make sense, the real wage must be increasing over time. For simplicity we assume a constant population and the existence of sufficient unemployed labor (partial unemployment of workers who have a job or households whose members are partly unemployed and partly employed) to avoid labor bottlenecks during the relevant time span.

\footnotetext{
${ }^{1}$ It may be remarked that this assumption arbitrarily rules out an influence of sectoral prices on sectoral growth rates. The assumption is certainly made for simplicity reasons, but note that if sectors and consumption categories are sufficiently wide (so to allow for substitutes) such an influence is not particularly relevant.
} 
3. The problem of prices in the dynamic model received from Leontief much less attention than the one he gave to produced quantities.

4. We use the expression sustainability prices to remind that prices of our second equation above permit producers to break even after paying all costs (wage and current input costs, plus capital costs). Similarly, we may speak of sustainability profits to mean profits that cover (at least) capital costs. Pasinetti called my attention on the fact that what here is called sustainability prices fully corresponds to the natural prices discussed in his 1981 book. The only reason why it may be worth maintaining the term sustainability is that the perspective of this note is simply searching for the implications of the firm (or sector) constraints, whereas Pasinetti's perspective is his methodological program of separating what in economic theory is required by nature from what is to be ascribed to institutions.

5. The fact that investment costs are covered by prices in the same period in which they are incurred is not to be regarded as surprising. For the purpose of long run analysis the model portrays a world where the sectoral growth is streamlined over a given time horizon and sectoral investment shares the same feature. Therefore the immediate addition of capital adjustment costs to the current production costs is reasonable.

6. The causal relation between investment and income distribution (profits) represents a cornerstone of the Cambridge (UK) Keynesian macroeconomics. Reaching this relation starting from the firm (or sectoral) level is probably the most direct way to get the result.

7. Not only in the model we discuss, but also in the real world, it should be clear that the distinction between financial sources (such as shares or bonds) has no relation at all with the overall amount of the capital adjustment costs. Over the time in fact sustainability requires that the flow of gross profits (sales net of labour and current input costs) obtained by a firm equals, period by period or in terms of present value, the flow of capital investment costs.

8. Long run prices in the ordinary sense of the expression must be sustainability prices (because a firm cannot survive if, on average, its profits do not match its investments). This applies irrespective of whether we are or we are not in a competitive environment.

9. Differently from other price equations in general, and also from other price equations in the context of the input-output theory, in our price equation sectoral prices depend upon the sectoral growth rates. In other words the faster a sector grows the higher, other things being equal, is the price level of its product. At first sight this may look perplexing, but it turns out to be quite reasonable if we consider that sustainability prices must include sustainability profits (that at their turn depend on sectoral growth rates).

10. Different rates of profit: how can sectoral profit rates differ from one another and why competition does not equalize them? We simply run over this question. True that we generally think of competition as characterized by a uniform profit rate, but this happens when we are in a lasting equilibrium. Out of this situation firms are price setters. In the present case the economic system is evolving according to different sectoral growth rates and firms (sectors) can impose convenient sustainability profit rates. Many complementary learning mechanisms may 
be conceived. Consider in addition that situations characterized by different sectoral profit rates are not exceptional. This may happen in presence of sectoral asymmetries. For example, when non-producible resources are taken into account (such as Ricardo's differently fertile lands), the profits (gross of rents) of different producers cannot be equalized (as in Quadrio Curzio and Pellizzari 1999, chapter 11).

11. Short run: we are only concerned with the long run sustainability path of prices and quantities in a Leontief-type dynamic model. Exploring how the short run behavior of individual decision makers (firms and households) may be influenced by the long run path is beyond the intent of this note.

12. Finally the price equation of the dynamic Leontief model we are discussing lends itself to an interesting interpretation in terms of labour theory of value. To proceed in this direction one should set the wage rate equal to one: this implies to express every price in units of working time. The deep meaning of these sectoral labour prices has been illustrated by Pasinetti $(1973,1988)$ through virtual static subsystems and virtual growing subsystems that permit to introduce the concepts of vertically integrated sectors (in static models) and vertically hyperintegrated sectors (in dynamic models).

\section{References}

D'Adda C (2015) Producible resources and producibility prices in a dynamic Leontief-type model. In: Baranzini M, Rotondi C, Scazzieri R (eds) Resources, production and structural dynamics. Cambridge University Press, Cambridge, pp 126-135

Pasinetti L (1963) A multisector model of economic growth. King's College, Cambridge, pp 1-59

Pasinetti L (1973) The notion of vertical integration in economic analysis. Metroeconomica 25:1-29

Pasinetti L (1981) Structural change and economic growth. Cambridge University Press, Cambridge, pp $1-281$

Pasinetti L (1988) Growing sub-systems, vertically hyper-integrated sectors and the labour theory of value. Cambridge J Econ 12:125-134

Quadrio Curzio A, Pellizzari F (1999) Rent, resources, technologies. Springer, Berlin, Heidelberg, pp 1-259 